\title{
Electrophysiological Signatures of Spatial Boundaries in the Human Subiculum
}

\author{
Sang Ah Lee, ${ }^{1}$ Jonathan F. Miller, ${ }^{2}$ Andrew J. Watrous, ${ }^{2}$ Michael R. Sperling, ${ }^{3}$ Ashwini Sharan, ${ }^{3}$ Gregory A. Worrell, ${ }^{4}$ \\ - Brent M. Berry, ${ }^{4}$ Joshua P. Aronson, ${ }^{5}$ ㅈathryn A. Davis, ${ }^{6}{ }^{\text {O}}$ Robert E. Gross, ${ }^{9}$ Bradley Lega, ${ }^{10}$ Sameer Sheth, ${ }^{11}$ \\ Sandhitsu R. Das, ${ }^{6}$ Joel M. Stein, ${ }^{7}$ Richard Gorniak, ${ }^{12}$ Daniel S. Rizzuto, ${ }^{8}$ and ${ }^{\circ}$ Joshua Jacobs ${ }^{2}$ \\ ${ }^{1}$ Department of Bio and Brain Engineering, Korea Advanced Institute of Science and Technology, Daejeon 34141, Korea, ${ }^{2}$ Department of Biomedical \\ Engineering, Columbia University, New York, New York 10027, ${ }^{3}$ Jefferson Comprehensive Epilepsy Center, Thomas Jefferson University, Philadelphia, \\ Pennsylvania 19107, ${ }^{4}$ Department of Neurology, Mayo Clinic, Rochester, Minnesota 55902, ${ }^{5}$ Department of Surgery, Dartmouth-Hitchcock Medical Center,

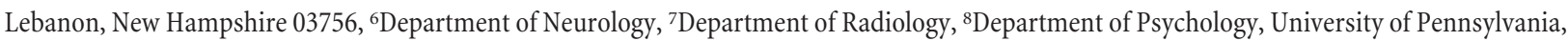 \\ Philadelphia, Pennsylvania 19104, ${ }^{9}$ Department of Neurosurgery, Emory University, Atlanta, Georgia 30322, ${ }^{10}$ Department of Neurological Surgery, \\ University of Texas Southwestern Medical Center, Dallas, Texas 75235, ${ }^{11}$ Department of Neurosurgery, Baylor College of Medicine, Houston, Texas 77030, \\ and ${ }^{12}$ Department of Radiology, Thomas Jefferson University, Philadelphia, Pennsylvania 19107
}

Environmental boundaries play a crucial role in spatial navigation and memory across a wide range of distantly related species. In rodents, boundary representations have been identified at the single-cell level in the subiculum and entorhinal cortex of the hippocampal formation. Although studies of hippocampal function and spatial behavior suggest that similar representations might exist in humans, boundary-related neural activity has not been identified electrophysiologically in humans until now. To address this gap in the literature, we analyzed intracranial recordings from the hippocampal formation of surgical epilepsy patients (of both sexes) while they performed a virtual spatial navigation task and compared the power in three frequency bands $(1-4,4-10$, and $30-90 \mathrm{~Hz})$ for target locations near and far from the environmental boundaries. Our results suggest that encoding locations near boundaries elicited stronger theta oscillations than for target locations near the center of the environment and that this difference cannot be explained by variables such as trial length, speed, movement, or performance. These findings provide direct evidence of boundary-dependent neural activity localized in humans to the subiculum, the homolog of the hippocampal subregion in which most boundary cells are found in rodents, and indicate that this system can represent attended locations that rather than the position of one's own body.

Key words: boundary; cognitive map; human subiculum; intracranial EEG; navigation; theta oscillations

Significance Statement

Spatial computations using environmental boundaries are an integral part of the brain's spatial mapping system. In rodents, border/ boundary cells in the subiculum and entorhinal cortex reveal boundary coding at the single-neuron level. Although there is good reason to believe that such representations also exist in humans, the evidence has thus far been limited to functional neuroimaging studies that broadly implicate the hippocampus in boundary-based navigation. By combining intracranial recordings with high-resolution imaging of hippocampal subregions, we identified a neural marker of boundary representation in the human subiculum.

\section{Introduction}

Research across a wide range of disciplines has converged on the notion that environmental boundaries strongly influence spatial memory and cognition (Lee, 2017). When animals lose track of where they are, they rely heavily on boundary structures to find

Department of Defense or the U.S. Government. We thank Colin Lever, Shachar Maidenbaum, and two anonymous reviewers for their comments and suggestions.

The authors declare no competing financial interests.

Correspondence should be addressed to either of the following: Sang Ah Lee, Department of Bio and Brain Engineering, Korea Advanced Institute of Science and Technology, 291 Daehak-ro, Yuseong-gu, Daejeon 34141, Republic of Korea, E-mail: sangah.lee@kaist.ac.kr; or Joshua Jacobs, Department of Biomedical Engineering, Columbia University, 1210 Amsterdam Avenue, New York, NY 10027, E-mail: joshua.jacobs@columbia.edu.

https://doi.org/10.1523/JNEUROSCI.3216-17.2018

Copyright $\odot 2018$ the authors $\quad 0270-6474 / 18 / 383265-08 \$ 15.00 / 0$ 
their way back to the goal (for review, see Cheng and Newcombe, 2005; Lee and Spelke, 2010; Tommasi et al., 2012). Nonboundary features such as objects and surface properties also influence navigation but are used primarily as beacons (Lee et al., 2006), contextual cues (Julian et al., 2015), and error-correcting landmarks in path integration (Etienne et al., 1996). To explain the effect of boundaries in behavior, theorists have proposed that the 3D structure of the environment provides a reliable basis for metric distance computations in spatial mapping (Cheng, 1986; Gallistel, 1990).

Electrophysiological recordings in the rodent hippocampal formation have shown that the spatial coding by place cells and grid cells is highly influenced by environmental boundaries (O'Keefe and Burgess, 1996; Lever et al., 2002; Hardcastle et al., 2015; Krupic et al., 2015; Stensola et al., 2015). Boundary-based models of place mapping (Hartley et al., 2000; Barry et al., 2006) explain the firing fields of place cells as a sum of distance inputs from nearby boundaries and the existence of boundary cells in the rodent subiculum (Lever et al., 2009) and border cells in the entorhinal cortex (EC) (Solstad et al., 2008) provide evidence of boundary representations at the single-neuron level. Although a small percentage of boundary cells encode boundaries from distances up to $\sim 20-30 \mathrm{~cm}$, they are most often characterized by their increased firing in response to nearby boundary structures, such as walls, drop-offs, and traversable gaps on the floor (Lever et al., 2009; Stewart et al., 2014). Like other spatial cells, they are theta modulated and they develop in rat pups at the same time as place cells and earlier than grid cells (Bjerknes et al., 2014; Muessig et al., 2015).

Despite the fact that boundary cells have yet to be found in the human brain, behavioral experiments suggest that we share similar boundary-based navigational mechanisms with other animals. For an extended period in human development, boundaries exert a dominant influence on spatial mapping (HermerVazquez et al., 2001). Such boundaries are not limited to large walls, but also include subtle 3D structures such as traversable ridges and curbs (Lee and Spelke, 2008, 2011), similar to the characteristics of boundary cells in rodents discussed above. The use of environmental boundaries can also be seen in adults (Hermer-Vazquez et al., 1999; Hartley et al., 2004) and functional neuroimaging studies have established that boundary-based navigation or imagery engages the hippocampus (Doeller et al., 2008; Bird et al., 2010). Other studies have identified boundary representation of visual scenes and its role in navigation upstream from the hippocampus (Park et al., 2011; Ferrara and Park, 2016; Julian et al., 2016).

Challenges to single-cell recording in humans can be partially bypassed by looking for signatures of neural activity that would be visible at the population level. An example of this is the hexagonally symmetrical fMRI response in the entorhinal cortex that might be attributed to populations of grid cells (Doeller et al., 2010). Similarly, neural signals of boundary representations could also be visible at the population level because of their clustered activity when an animal is near a boundary (Solstad et al., 2008; Lever et al., 2009). Despite the availability of direct intracranial EEG recordings from the human medial temporal lobe during computer-based navigation tasks (Ekstrom et al., 2005; Watrous et al., 2011; Miller et al., 2013; Vass et al., 2016), no studies thus far have shown direct neural signatures of boundary representation in humans. In the present study, we recorded the local field potential (LFP) from surgical epilepsy patients engaged in a computer-based navigation task, combined with a high-resolution electrode localization method, to investigate boundary-related signals in the human brain in specific subregions of the hippocampal formation (i.e., CA1, dentate gyrus, subiculum, EC, and perirhinal cortex). We capitalized on the fact that boundary cells, like other spatial cells, are theta modulated (Lever et al., 2009) and that most boundary cells respond to locations near boundaries. Because hippocampal neurons represent intended target locations (Hok et al., 2007; Howard et al., 2014; Chadwick et al., 2015), the strength of theta oscillations while subjects encode a single target location over an extended period (over the course of an entire trial) could indicate the neural representation of its spatial location (McFarland et al., 1975; McNaughton et al., 1983; Rivas et al., 1996; Czurkó et al., 1999; Terrazas et al., 2005). Therefore, in the present study, we compared oscillatory power in three frequency ranges that have been previously implicated in spatial navigation and memory in humans (Nyhus and Curran, 2010; Watrous et al., 2013; Jacobs, 2014), 1-4 Hz ("low-theta" or "delta"), 4-10 Hz ("theta"), and $30-90 \mathrm{~Hz}$ ("gamma"), as subjects attended to target locations near or far from the boundaries of the virtual environment over a 5-s-long encoding period.

\section{Materials and Methods}

Participants. The subjects in our study were 58 epilepsy patients (27 males, 31 females) between the ages 18 and 65 who had electrodes surgically implanted to localize seizure foci and to guide potential surgical treatment. Subjects performed a virtual navigation task on a laptop computer as their neural activity was recorded at a sampling rate of $500 \mathrm{~Hz}$ or above (Jacobs and Kahana, 2010). Electrodes were implanted in various brain regions as dictated by clinical needs; for analysis of neural measurements, we selectively analyzed 39 of the patients who had electrodes in our five regions of interest: CA1, dentate gyrus, subiculum, EC, and perirhinal cortex. These regions were chosen because they were the top five hippocampal subregions with the most number of electrodes implanted; 39 subjects had electrodes in those regions. The same methods were applied at seven testing sites: Thomas Jefferson University Hospital (Philadelphia, PA), Mayo Clinic (Rochester, MN), University of Texas Southwestern (Dallas, TX), Dartmouth-Hitchcock Medical Center (Lebanon, NH), University of Pennsylvania Medical Center (Philadelphia, PA), Emory University Hospital (Atlanta, GA), and Columbia University Medical Center (New York, NY). Each subject provided informed consent before participation. Our multisite study was approved by local institutional review boards, as well as the institutional review board of the University of Pennsylvania (data coordination site) and the Human Research Protection Office at the Space and Naval Warfare Systems Command Systems Center Pacific. Data from five subjects who responded randomly in the task (see below for details) were excluded from our analysis.

Spatial navigation task. Subjects performed a computer-based spatial memory task (Jacobs et al., 2016) in a virtual rectangular arena (approximately equivalent to $19 \mathrm{~m} \times 10.5 \mathrm{~m}$ ) with 4 distal visual cues for orienting. Each $5 \mathrm{~s}$ encoding trial ( 96 trials per session, $1-3$ sessions per subject) was preceded by a $2 \mathrm{~s}$ period during which subjects were presented with a still scene of the environment. At the start of the trial, a target object appeared on screen and subjects were automatically rotated (1 s duration) and driven toward it ( $3 \mathrm{~s}$ duration, constant speed) until they were stopped at the target location (1 s duration). This 5-s-long encoding period took place twice and from two different viewpoints in the environment (chosen randomly from a range of locations that would fit the $3 \mathrm{~s}$ of driving and $1 \mathrm{~s}$ of rotating). The two encoding periods were separated by a $5 \mathrm{~s}$ black screen. After another $5 \mathrm{~s}$ delay, subjects were transported to a different randomly chosen location from which they had to drive themselves back using a joystick to the now hidden target and press a response button. Subjects received feedback on their responses by means of a simple rectangular depiction of the environment with the target and response locations marked as circular points (see Fig. 1A). The automatized design of the encoding phase ensured that all aspects of a subject's movement (time, speed, distance, visual flow, and movement) were identical across trials (and across target locations) while maximizing the number of trials. 


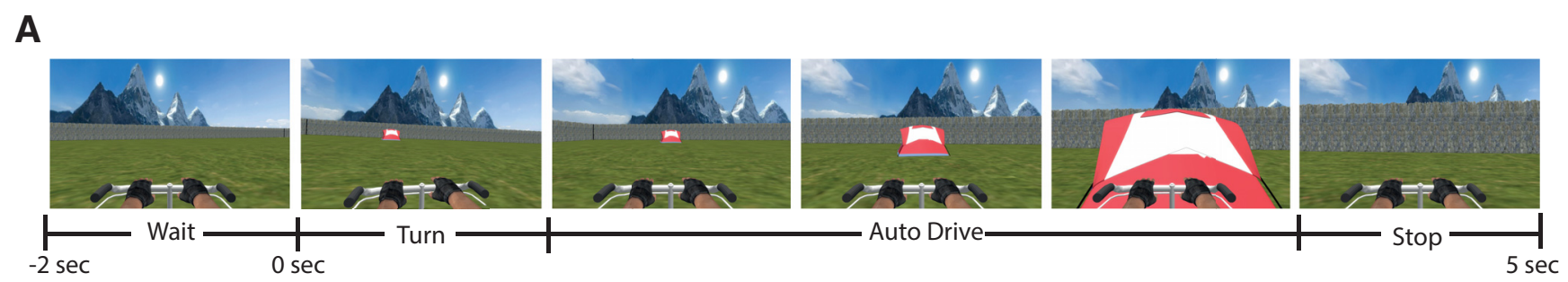

B

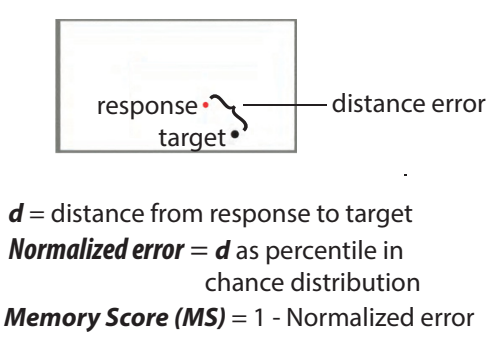

C

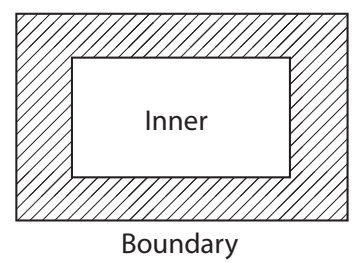

Equal area

Same aspect ratio
D

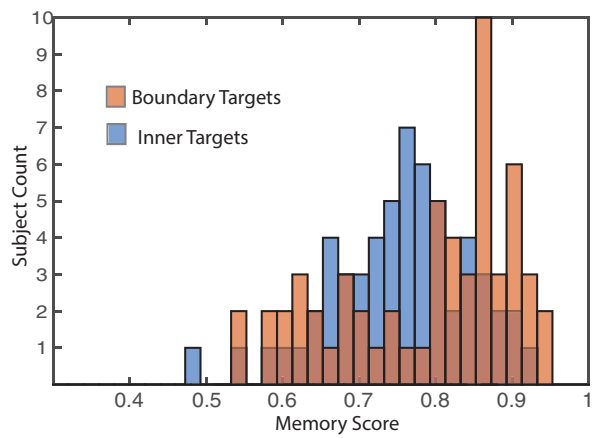

Figure 1. A, Each trial began with a 2 s stationary wait period during which the subject viewed the environment. Once the target object appeared, the subject had $5 \mathrm{~s}$ of encoding, during which the subject (in the virtual reality environment) was automatically rotated toward and then driven to the target location. This was repeated from a different starting point such that there were two encoding trials for each target location. After the encoding trials, subjects were transported to a new starting point for the test phase and asked to drive themselves back to the target location and respond by pressing a button. Feedback was provided by displaying a map of the target and response location, along with game points that correlated with distance error. $\boldsymbol{B}$, We computed an MS based on the accuracy percentile with respect to the chance distribution of responses for each target location. $\boldsymbol{C}$, Target locations were categorized as being boundary or inner by dividing the rectangular environment into two equal areas with equal aspect ratios. $D$, Subjectwise distributions of memory scores for boundary and inner trials, which indicate that subjects performed better on boundary trials overall.

Electrode localization. Before surgical electrode implantation, we acquired high-resolution structural magnetic resonance imaging (MRI) scans of the hippocampus and medial temporal lobe from each subject ( $0.5 \mathrm{~mm}$ by $0.5 \mathrm{~mm}$ by $2 \mathrm{~mm}$ ). The hippocampal subregions and extrahippocampal cortical regions were automatically defined and labeled on these scanned images using a multi-atlas-based segmentation technique (Wang et al., 2013; Yushkevich et al., 2015). After the electrode implantation, a neuroradiologist identified each electrode contact using a postimplant CT scan. The MRI and CT scans were coregistered using Advanced Normalization Tools (Avants et al., 2008) and the neuroradiologist visually confirmed and provided additional detail on the localization and anatomical label for each contact (Duvernoy, 2005).

Statistical analysis of behavior. We measured patients' memory performance in a way that accounted for unequal distribution of possible distance errors across the environment. An example of this issue is that objects at the far ends of the environment have a larger maximum possible error distance compared with objects in the center. In our approach, we measured performance for each response by computing a memory score (MS), which normalizes for overall difficulty across target locations by computing the actual response's rank relative to a distribution of a chance distribution based on 100,000 randomly generated response locations. This means that an MS of 1 corresponds to a perfect response $(0$ error), an MS of 0 corresponded to the worst possible response, and an MS of 0.5 was chance). We then divided the environment into two equal regions, an outer rectangular ring ("boundary") and a central area ("inner"), and compared subjects' mean MS between the two zones (see Fig. $1 C, D)$. To select only those subjects who understood and were able to perform the task, we discarded data from five subjects who performed overall at chance level ( $t$ tests against chance MS of 0.5 , n.s.).

Statistical analysis of neural signals. To examine neural activity for successfully encoding of both boundary and inner locations selectively, we discarded all trials in which subjects scored below the mean MS across all subjects (MS < 0.73 ) to reduce noise from trials in which the subject was inattentive or disoriented. As mentioned in the previous section, we discarded subjects who performed overall at chance; additionally, we only included subjects who had at least five trials in each category (boundary/inner) to ensure sufficient sampling. This left us with 37 sub- jects, all with at least 20 trials in each category (average of 64.5 boundary trials and 65.2 inner trials).

First, the raw data were notch filtered using a Butterworth filter at 60 $\mathrm{Hz}$ and the oscillatory power at each electrode in three frequency bands, low-theta $(1-4 \mathrm{~Hz})$, theta $(4-10 \mathrm{~Hz})$, and gamma $(30-90 \mathrm{~Hz})$, was extracted through a Hilbert transform (Freeman, 2007). We then computed the time-averaged power in each band across the $5 \mathrm{~s}$ encoding period. The power values were then $z$-scored according to the mean power in that electrode over all encoding periods in the session.

We averaged the power over all electrodes from the same hemisphere of a single patient, such that we took one measurement from each hemisphere and used these as the input to our ANOVA. This was done to prevent double-sampling from shared signal sources within different contacts on a subject's medial temporal lobe within one hemisphere. Using this method, we had 18 subiculum hemispheric samples (12 in left hemisphere, LH) from 15 patients (i.e., 3 patients with bilateral subiculum electrodes), 18 entorhinal samples (13 in LH) from 14 patients, 43 CA1 samples ( 25 in LH) from 37 patients, 23 dentate gyrus samples ( 15 in LH) from 21 patients, and 29 perirhinal samples (20 in LH) from 22 subjects.

\section{Results}

\section{Behavior}

If boundaries are crucial to the neural representation of spatial location, then subjects should generally be more accurate in their performance for target locations near boundaries than for locations far from boundaries (Hartley et al., 2004). To test the degree to which subjects rely on the environmental boundaries to perform our task, we divided the environment into two regions with equal areas, the boundary and the inner areas (Fig. 1C) and compared subjects' performance as quantified by their MS (see Materials and Methods for details). A repeated-measures ANOVA with target location (boundary vs inner) as the within-subjects variable and sex as the between-subjects variable found significantly better performance for boundary than inner trials $\left(F_{(1,56)}=9.94\right.$, 
A

B

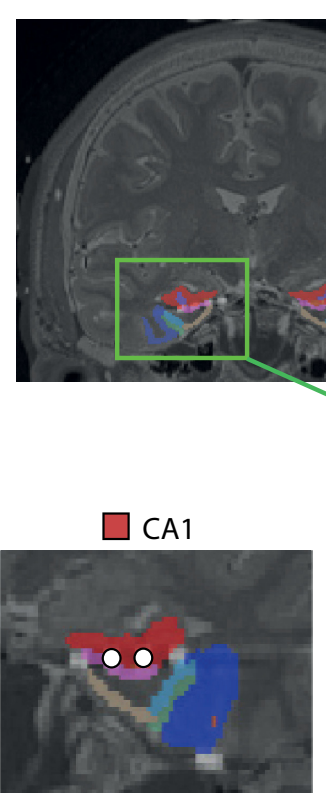

$\mathrm{n}=43$

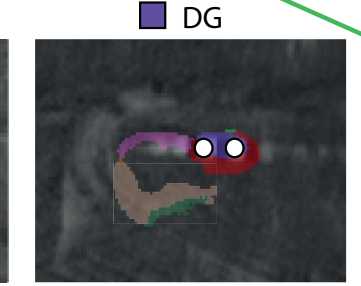

$\mathrm{n}=23$

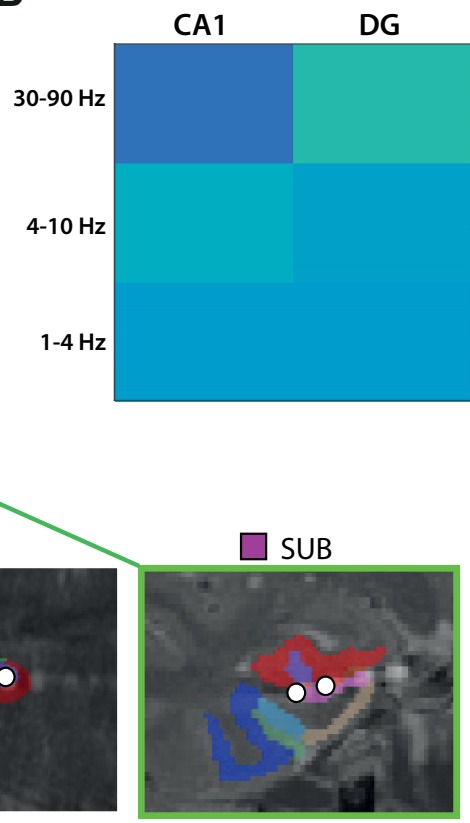

$\mathrm{n}=18$

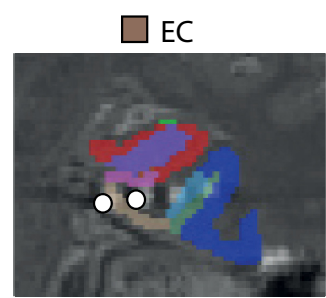

$\mathrm{n}=18$
EC

PRC

SUB

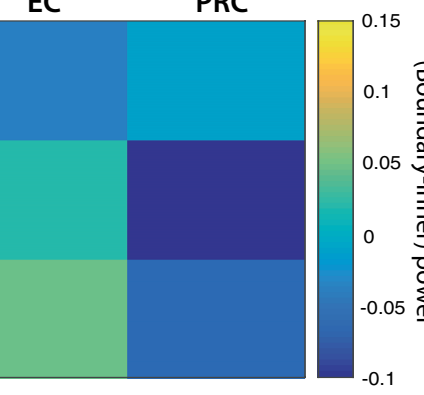

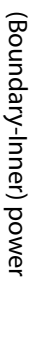

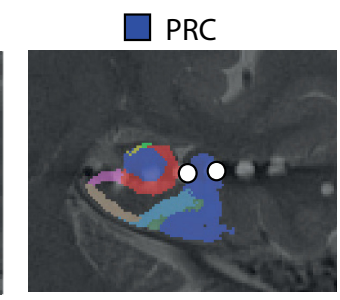

$\mathrm{n}=29$

Figure 2. $\quad \boldsymbol{A}$, Electrodes were localized by combining presurgical high-resolution structural MRI and postimplant CT scans. The hippocampal subregions are labeled and shaded in color and the bipolar electrode contact pairs (distance $1.5 \mathrm{~mm}$ ) centered at each subregion are marked with white dots. Images are from Patient 1066P. $\boldsymbol{B}$, Encoding boundary locations elicited higher power in low-frequency oscillations than inner locations. Z-scored power differences between boundary and inner target locations are plotted for three frequency bands: low-theta ( $1-4 \mathrm{~Hz}$ ), theta (4-10 $\mathrm{Hz}$ ), and gamma $(30-90 \mathrm{~Hz})$. There was a significant boundary $\times$ frequency interaction that was specific only to the subiculum $\left(F_{(2,34)}=4.71, p=0.016\right)$ and present in no other region.

$p=0.003$; Fig. $1 D)$. These results are consistent with the interpretation that boundaries have a significant influence on the computation of spatial location and indicate that our virtual reality task sufficiently engaged those underlying navigational mechanisms. There was no significant effect of $\operatorname{sex}\left(F_{(1,56)}=2.71\right.$, $p=0.11)$ and no location $\times$ sex interaction $(F<1$, n.s. $)$.

\section{Neural results}

A repeated-measures ANOVA was conducted to determine at the population level whether neural signals at three frequency ranges $(1-4,4-10$, and $30-90 \mathrm{~Hz})$ varied according to the presence of a nearby boundary across five different subregions of the hippocampus (CA1, dentate gyrus, subiculum, EC, perirhinal cortex; Fig. 2A). Critically, we found that LFP power across all electrodes significantly varied according to whether the patient encoded a target location near or far from a boundary, at particular frequency ranges and localized to a particular region (boundary $X$ frequency $\times$ region interaction: $\left.F_{(8,248)}=1.99, p=0.047\right)$ (Fig. $2 B$ ). There was no main effect (nor significant interactions) of sex $\left(F_{(1,119)}=1.11, p=0.30\right)$. Upon closer inspection of each region, the boundary $X$ frequency effect was specific to the subiculum $\left(F_{(2,34)}=4.71, p=0.016, \eta\right.$-squared $\left.=0.22\right)$ and significant in no other region (all $F<2, p>0.2$ ).

Focusing on the subiculum, an average power spectrum difference plot of boundary-inner trials across all subjects (Fig. 3A) revealed two peaks in the frequencies in which boundary trials elicit higher power than the inner trials. $t$ tests for our three frequency bands revealed that encoding target locations near boundaries elicited greater theta power than encoding inner locations (4-10 $\mathrm{Hz}: t_{(17)}=3.22, p=0.015$, Bonferroni-corrected; Fig. $3 B$ ), but that this effect was only marginally significant in the $1-4 \mathrm{~Hz}$ low-theta band $\left(t_{(17)}=2.58, p=0.057\right.$, Bonferroni-corrected) and not significant in the $30-90 \mathrm{~Hz}$ gamma band $\left(t_{(17)}<1\right.$, n.s.).
We next examined this boundary-related signal at the level of individual hemispheric measurements and subjects. Fifteen of 18 hemispheric subiculum measurements showed greater theta power for navigating to boundary locations than inner locations (binomial test, $p=0.008$ ) in 12 of 15 subjects (binomial test, $p=$ $0.035)$. Across all subjects, there was a significant negative correlation between LFP power on each trial and distance from the target location to the closest boundary for both low-theta $(1-4 \mathrm{~Hz}$, mean $\beta$ weight $=-0.016, t_{(17)}=2.54, p=0.042$, Bonferronicorrected $)$ and theta $\left(4-10 \mathrm{~Hz}\right.$, mean $\beta$ weight $=-0.019, t_{(17)}=$ 2.54, $p=0.041$, Bonferroni-corrected), showing that the target location's proximity to the environmental walls elicited stronger signals in those frequencies (Fig. 3C). This indicates that the boundary effect found above is not an artificial consequence our particular designation of boundary and inner regions (Fig. 3D). In some cases, the boundary effect was significant even at the single-electrode level (Fig. 4).

There were no sex differences in the boundary theta effect in the subiculum $(F<1$, n.s. $)$. Because only six of the 18 subicular samples were from the right hemisphere, we did not have sufficient power to test for hemispheric differences.

As a control to ensure that the difference between boundary and inner trials is truly driven by the target, we analyzed the LFP signals during the first $2 \mathrm{~s}$ of each trial, when the subject was standing within the virtual environment with no target object $(-2$ to $0 \mathrm{~s}$ before the start of the encoding period; Fig. $1 A)$. As expected, before the target location appeared on screen, there were no differences between the boundary and the inner region (all $t<1$, n.s.). In addition, to determine whether neural activity was modulated with respect to the subject's own location during that $2 \mathrm{~s}$ period, we compared LFP as a function of the subject's position (rather than the target position) in the virtual space. We 
A

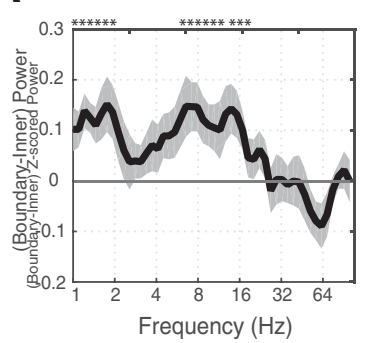

B

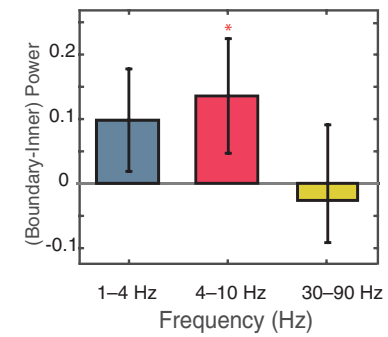

C

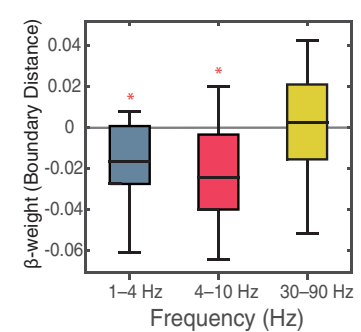

E

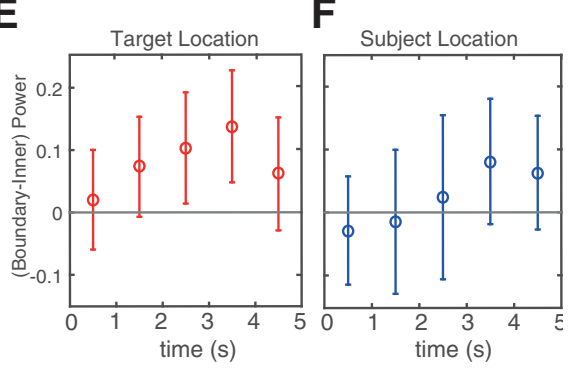

D

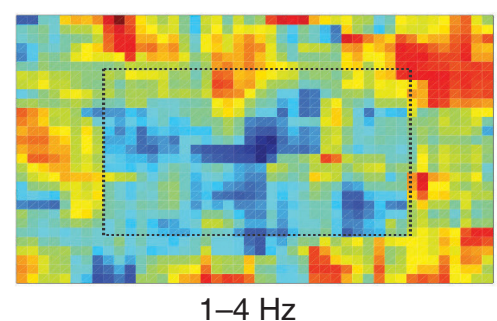

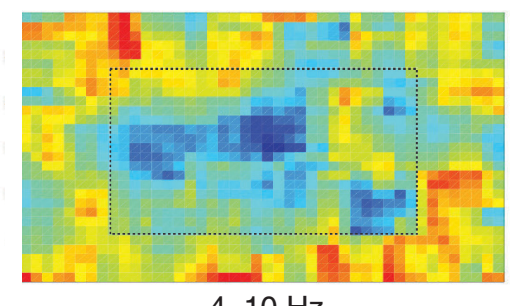

4-10 Hz

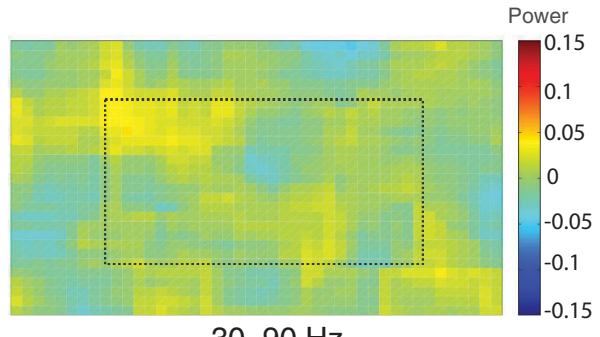

30-90 Hz

Figure 3. A, Power-frequency plot of normalized power differences in the subiculum between boundary and inner target locations. Asterisks indicate parts of the spectra where boundary and inner trials significantly differ ( $t$ tests at each frequency, $p<0.05)$. $B$, Boundary-inner power difference in three frequency bands: low-theta $(1-4 \mathrm{~Hz})$, theta $(4-10 \mathrm{~Hz})$, and gamma $(30-90 \mathrm{~Hz})$. Error bars indicate $95 \%$ confidence intervals. Targets near boundaries elicit stronger theta oscillations than those far from boundaries. $C$, Mean $\beta$ coefficients for best fit lines predicting power by distance to the nearest boundary across all hemispheric measurements. Asterisks indicate statistically significant difference from 0. $D$, Overhead heatmaps of the environment plotting average $z$-scored power for the three observed frequency bands at each target object location. The environment was binned into a $45 \times 30$ rectangular grid and computed average power in each bin for each subicular sample. Individual heat maps were smoothed with a 2D Gaussian kernel (width $=7$ ) and then averaged across all samples. Dotted lines indicate the boundary-inner division. $\boldsymbol{E}$, Boundary-inner theta power across the $5 \mathrm{~s}$ of encoding with respect to the target location. $\boldsymbol{F}$, Boundary-inner theta power across the $5 \mathrm{~s}$ of encoding, with respect to the subject location (right). Error bars indicate $95 \%$ confidence intervals.

found no effects of boundary proximity in any frequency band (all $t<1.5$, n.s.).

We also considered the possibility that our effects may be related to movement. Figure $3 E$ displays the boundary-inner theta power difference for the target location over the course of the $5 \mathrm{~s}$ encoding period. Although the boundary effect for target location seems higher during the auto drive phase (2-4 s; Fig. 1A) than the turn and stop phases (1-2 s, 4-5s), an analysis of boundary-inner differences separating out these two modes of movement (driving vs nondriving) shows that, whereas there was a significant effect of boundary $\left(F_{(1,17)}=8.78, p=0.009\right)$, there was no significant effect of movement $\left(F_{(1,17)}<1\right.$, n.s. $)$ or movement by boundary interaction $\left(F_{(1,17)}=1.35, p=0.26\right)$.

In contrast to the target location, we saw no theta power modulation as a function of the subject's own location (Fig. $3 F$ ). There were no theta power differences for boundary and inner subject locations across each second of the encoding period (all $t<1.8$, n.s.); an ANOVA comparing the boundary-inner difference in theta power for the target location (Fig. $3 E$ ) and the subject location (Fig. $3 F$ ) confirmed that the boundary effect was significantly higher for the target location (boundary effect $\times$ location: $\left.F_{(1,17)}=4.69, p=0.04\right)$.

Although we excluded the trials with memory scores below mean performance (MS $<0.73$ ) in the above analyses, it is still possible that the difference in theta power between the boundary categories simply reflected performance differences between boundary and inner locations (as opposed to boundary proximity per se). If this were true, then we should also see theta effects related to performance within the same boundary category (i.e., even for just inner locations, good trials should exhibit higher theta power than bad trials). To test this, we compared LFP power between the "good" trials (MS > 0.73) and (the previously excluded) "bad" trials (MS < 0.73 ) separately for each boundary category. We found no performance effects for either boundary or inner trials (all $t \leq 1.2$, n.s.), suggesting that subicular theta was not linked directly to performance. In fact, even the bad boundary trials elicited significantly higher theta power than the good inner trials $\left(t_{(17)}=2.57, p=0.02 ; t<1.1\right.$ for low-theta and gamma).

Finally, although we had selectively chosen to analyze the good trials to examine only successfully encoded cases with MS > 0.73 , we confirmed that the boundary-related theta effect was present even when all trials were included $\left(\mathrm{MS}>0 ; t_{(17)}=2.91\right.$, $p=0.03$, corrected). Nevertheless, unlike the good trials, the boundary effect was not significant $(t<1$, n.s.) for bad trials with MS $<0.73$, suggesting that the boundary effect was disrupted when memory encoding was poor, perhaps due to reasons such as fatigue, disorientation, or distraction.

\section{Discussion}

Our analysis of the LFP at various hippocampal subregions reveals for the first time in humans that the subiculum may play a key role in boundary-based spatial mapping. This finding extends previous neuroimaging studies implicating the human hippocampus in boundary-based navigation (Doeller et al., 2008; Bird et al., 2010) and is convergent with single-unit recording of boundary cells in the rodent subiculum (Lever et al., 2009). Interestingly, although rodents have boundary-related cells in both subiculum (Lever et al., 2009) and the EC (Solstad et al., 2008), we found boundary-related effects only in the former. One potential explanation for this difference is that the subiculum is more strongly involved than the EC in boundary-based spatial mapping. This account is consistent with rodent studies that reported a much higher percentage of boundary cells in the subiculum: (20-25\%; Lever et al., 2009; Olson et al., 2017) than in the EC (6-11\%; 
A
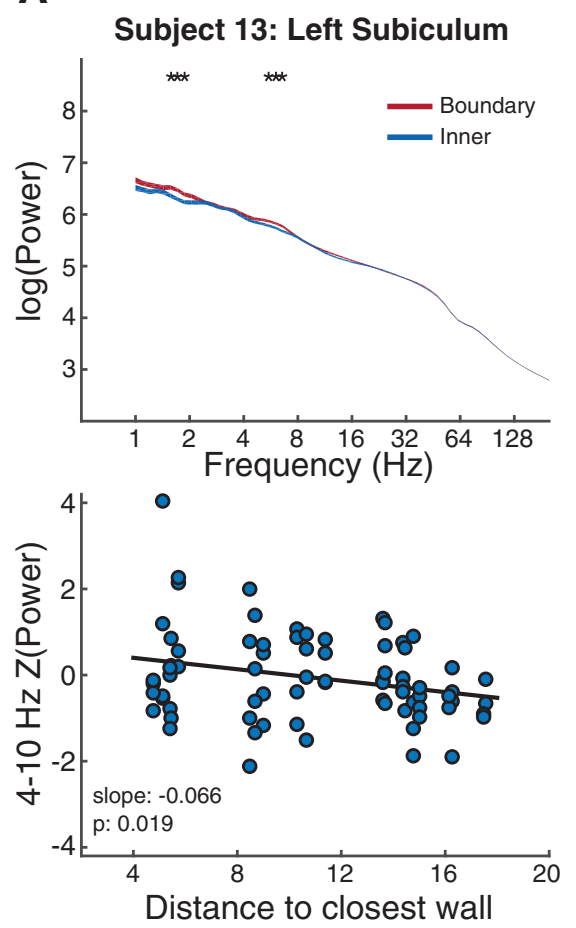

B

Subject 15: Left Subiculum
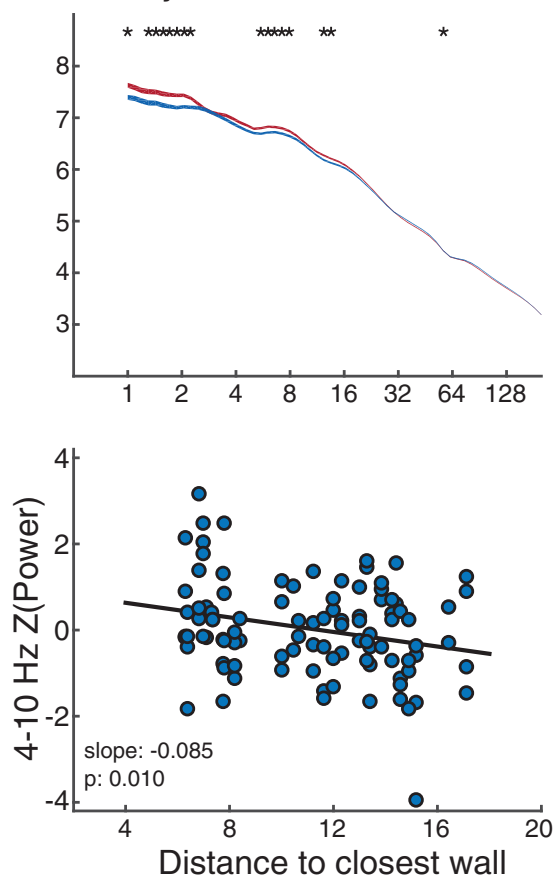

C

Subject 33: Right Subiculum
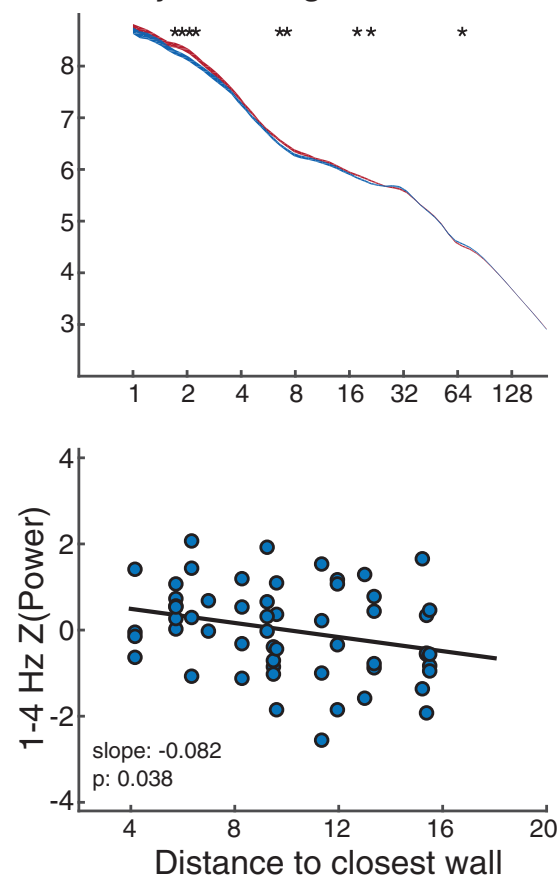

Figure 4. $\boldsymbol{A}-\boldsymbol{C}$, Each column shows an individual electrode from three different subjects. First row, Examples of power spectra from individual electrodes for boundary and inner trials. Line thickness indicates SE. Asterisks indicate parts of the spectra where boundary and inner trials significantly differ ( $t$ tests at each frequency, $p<0.05)$. Second row, Trial-by-trial plot of power in theta frequency oscillations for each corresponding electrode above it. Slopes of the best fit lines that negatively deviate from zero show that theta power is stronger at closer distances to a wall boundary.

Solstad et al., 2008; Boccara et al., 2010; Bjerknes et al., 2014; Tang et al., 2014).

Could the increase in theta power for boundary encoding be the result of increased activity from populations of human subicular boundary cells? Unlike other spatial cell types, which activate fairly evenly across an environment, the entire boundary-cell network is more active overall when representing particular areas of an environment (i.e., near boundaries). This coarse-grained spatial specificity in its firing properties is essential for our identification of boundary-related LFP activity. The theta effect that we observed might be broadly interpreted as a manifestation of boundary-based spatial encoding or navigation strategies. At the same time, however, it could signify the existence and dynamic activation of boundary-coding cells in the human subiculum. However, this type of boundary-related LFP signal change has not yet been analyzed in rodents, perhaps due to logistical confounds in performing this comparison such as the variable behaviors of rodents across the environment. For instance, animals run at higher mean speeds parallel to walls (Horev et al., 2007) and theta power increases with running speed (Rivas et al., 1996; Czurkó et al., 1999; Maurer et al., 2005), potentially making it difficult to isolate boundary-related theta effects in rodents.

The boundary-related theta patterns that we observed appeared during the encoding period of our task, when the target location was visible for $5 \mathrm{~s}$ as the subject was automatically moved toward it at a fixed velocity. Although this task design is different from traditional tests of navigation, we implemented this fixedmovement encoding period because it allowed us to equate for multiple perceptual, behavioral, and motoric factors across all trials and for all subjects (Jacobs et al., 2016). In other words, the boundary effect here cannot be attributed to differences in path length or shape, joystick control, speed, visual flow, timing, or trial length, to name just a few, between trial with boundary and inner targets. For the same reasons, we have chosen to analyze the encoding phase rather than the freely moving response phase, in which none of the above factors could be controlled.

The fact that our findings are specific to the target location rather than the subject location adds to the body of evidence suggesting a role for the hippocampal formation in goal representation (Hok et al., 2007; Howard et al., 2014; Chadwick et al., 2015) and attended, viewed, imagined, and planned spatial mapping (Rolls, 1999; Killian et al., 2012; Pfeiffer and Foster, 2013; Bellmund et al., 2016; Horner et al., 2016) of, not only oneself, but also other individuals (Danjo et al., 2018; Omer et al., 2018). Under different circumstances, however, it may be possible to detect boundary encoding with respect to self-location rather than the target location. Our task required subjects to maximally attend to the location of the target for the brief $5 \mathrm{~s}$ that it was on screen; moreover, the automated movement during the encoding period made it unnecessary for subjects to attend to their own navigation through space. A different task design requiring subjects to track and control their own position may detect boundary representations with respect to self-location (Ekstrom et al., 2003; Jacobs et al., 2013).

Past studies using human intracranial recordings have demonstrated the involvement of both low-theta (1-4 Hz) and theta $(4-10 \mathrm{~Hz})$ during both real and virtual navigation (M Aghajan et al., 2017; Bohbot et al., 2017) and low-frequency oscillations seem to be functionally involved in human memory and navigation (Watrous et al., 2013; Jacobs, 2014; Bush et al., 2017). Our boundary-related effects were mainly seen in the conventional $4-10 \mathrm{~Hz}$ range, where theta oscillations are commonly found in rodents. In contrast, we observed mixed results in the low-theta band, with a significant negative correlation between LFP power 
and distance to the nearest boundary. It is possible that both low-theta and theta bands may be implicated in spatial processing in humans and the use of visual tasks in virtual environments might play a role in some cases (Bohbot et al., 2017). The present results may provide further insight that guides future work on identifying potential functional differences between these two frequency ranges.

Another open question for further study involves the dissociation of theta power increases in the medial temporal lobe related to memory performance with those related to spatial representation (as we have found in this study). It is difficult to completely disentangle spatial encoding of boundaries to spatial memory, given that successful performance should be a functional consequence of successful spatial encoding after all. Nevertheless, our control analyses show that the theta increases that we have observed in this task are not solely attributable to memory performance. Moreover, the detailed localization of these effects to the subiculum make it unlikely that these theta effects are actually related to memory (which is a hippocampus-wide phenomenon) rather than to spatial boundaries.

Spatial mapping is one of the most essential survival skills for any self-locomoting animal and accurate metric representation of distance is essential to accurate place mapping; environmental boundaries, even in naturalistic terrains, provide a stable, invariant cue by which distance representations can be anchored and corrected (Gallistel, 1990). Researchers have suspected for nearly 70 years that even distantly related species such as rats and humans share cognitive and neural mechanisms that support such abilities (Tolman, 1948; O'Keefe and Nadel, 1978) and our results fill an important gap in the literature by identifying for the first time a highly localized neural representation of environmental boundaries in the human subiculum, just as in rats. Not only do these findings inform theories of common spatial coding in the vertebrate brain, they also give us another neural signature that we can use to investigate the flexible application of basic hippocampal representations in supporting abstract human conceptual knowledge (Spelke et al., 2010; Constantinescu et al., 2016; Jacobs and Lee, 2016; Garvert et al., 2017) and the cognitive impairments that result from their dysfunction (Bird et al., 2010; Lakusta et al., 2010).

\section{References}

M Aghajan Z, Schuette P, Fields TA, Tran ME, Siddiqui SM, Hasulak NR, Tcheng TK, Eliashiv D, Mankin EA, Stern J, Fried I, Suthana N (2017) Theta oscillations in the human medial temporal lobe during real world ambulatory movement. Curr Biol 27:3743-3751.e3. CrossRef Medline

Avants BB, Epstein CL, Grossman M, Gee JC (2008) Symmetric diffeomorphic image registration with cross-correlation: evaluating automated labeling of elderly and neurodegenerative brain. Medical Image Analysis 12:26-41. CrossRef Medline

Barry C, Lever C, Hayman R, Hartley T, Burton S, O'Keefe J, Jeffery K, Burgess N (2006) The boundary vector cell model of place cell firing and spatial memory. Rev Neurosci 17:71-97. Medline

Bellmund JLS, Deuker L, Schröder TN, and Doeller CF (2016) Grid-cell representations in mental simulation. eLife 5: pii: e17089. CrossRef Medline

Bird CM, Chan D, Hartley T, Pijnenburg YA, Rossor MN, Burgess N (2010) Topographical short-term memory differentiates alzheimer's disease from frontotemporal lobar degeneration. Hippocampus 20:1154-1169. CrossRef Medline

Bird CM, Capponi C, King JA, Doeller CF, Burgess N (2010) Establishing the boundaries: the hippocampal contribution to imagining scenes. J Neurosci 30:11688-11695. CrossRef Medline

Bjerknes TL, Moser EI, Moser MB (2014) Representation of geometric borders in the developing rat. Neuron 82:71-78. CrossRef Medline

Boccara CN, Sargolini F, Thoresen VH, Solstad T, Witter MP, Moser EI,
Moser MB (2010) Grid cells in pre- and parasubiculum. Nat Neurosci 13:987-994. CrossRef Medline

Bohbot VD, Copara MS, Gotman J, Ekstrom AD (2017) Low-frequency theta oscillations in the human hippocampus during real-world and virtual navigation. Nat Commun 8:14415. CrossRef Medline

Bush D, Bisby JA, Bird CM, Gollwitzer S, Rodionov R, Diehl B, McEvoy AW, Walker MC, Burgess N (2017) Human hippocampal theta power indicates movement onset and distance travelled. Proc Natl Acad Sci U S A 114:12297-12302. CrossRef Medline

Chadwick MJ, Jolly AE, Amos DP, Hassabis D, Spiers HJ (2015) A goal direction signal in the human entorhinal/subicular region. Curr Biol 25: 87-92. CrossRef Medline

Cheng K (1986) A purely geometric module in the rat's spatial representation. Cognition 23:149-178. CrossRef Medline

Cheng K, Newcombe N (2005) Is there a geometric module for spatial orientation? Squaring theory and evidence. Psychon Bull Rev 12:1-23. CrossRef Medline

Constantinescu AO, O'Reilly JX, Behrens TEJ (2016) Organizing conceptual knowledge in humans with a gridlike code. Science 352:1464-1468. CrossRef Medline

Czurkó A, Hirase H, Csicsvari J, Buzsáki G (1999) Sustained activation of hippocampal pyramidal cells by 'space clamping' in a running wheel. Eur J Neurosci 11:344-352. CrossRef Medline

Danjo T, Toyoizumi T, Fujisawa S (2018) Spatial representations of self and other in the hippocampus. Science 359:213-218. CrossRef Medline

Doeller CF, King JA, Burgess N (2008) Parallel striatal and hippocampal systems for landmarks and boundaries in spatial memory. Proc Natl Acad Sci U S A 105:5915-5920. CrossRef Medline

Doeller CF, Barry C, Burgess N (2010) Evidence for grid cells in a human memory network. Nature 463:657-661. CrossRef Medline

Duvernoy HM (2005) The human hippocampus: functional anatomy, vascularization and serial sections with MRI. New York, NY: Springer Science and Business Media.

Ekstrom AD, Kahana MJ, Caplan JB, Fields TA, Isham EA, Newman EL, Fried I (2003) Cellular networks underlying human spatial navigation. Nature 425:184-188. CrossRef Medline

Ekstrom AD, Caplan JB, Ho E, Shattuck K, Fried I, Kahana MJ (2005) Human hippocampal theta activity during virtual navigation. Hippocampus 15:881-889. CrossRef Medline

Etienne AS, Maurer R, Séguinot V (1996) Path integration in mammals and its interaction with visual landmarks. J Exp Biol 199:201-209. Medline

Ferrara K, Park S (2016) Neural representation of scene boundaries. Neuropsychologia 89:180-190. CrossRef Medline

Freeman W (2007) Hilbert transform for brain waves. Scholarpedia 2:1338. CrossRef

Gallistel CR (1990) The organization of learning. Cambridge, MA: MIT

Garvert MM, Dolan RJ, Behrens TE (2017) A map of abstract relational knowledge in the human hippocampal-entorhinal cortex. eLife 6:e17086. CrossRef Medline

Hardcastle K, Ganguli S, Giocomo LM (2015) Environmental boundaries as an error correction mechanism for grid cells. Neuron 86:827-839. CrossRef Medline

Hartley T, Burgess N, Lever C, Cacucci F, O’Keefe J (2000) Modeling place fields in terms of the cortical inputs to the hippocampus. Hippocampus 10:369-379. CrossRef Medline

Hartley T, Trinkler I, Burgess N (2004) Geometric determinants of human spatial memory. Cognition 94:39-75. CrossRef Medline

Hermer-Vazquez L, Spelke ES, Katsnelson AS (1999) Sources of flexibility in human cognition: dual-task studies of space and language. Cogn Psychol 39:3-36. CrossRef Medline

Hermer-Vazquez L, Moffet A, Munkholm P (2001) Language, space, and the development of cognitive flexibility in humans: the case of two spatial memory tasks. Cognition 79:263-299. CrossRef Medline

Hok V, Lenck-Santini PP, Roux S, Save E, Muller RU, Poucet B (2007) Goalrelated activity in hippocampal place cells. J Neurosci 27:472-482. CrossRef Medline

Horev G, Benjamini Y, Sakov A, Golani I (2007) Estimating wall guidance and attraction in mouse free locomotor behavior. Genes Brain Behav 6:30-41. CrossRef Medline

Horner AJ, Bisby JA, Zotow E, Bush D, Burgess N (2016) Grid-like processing of imagined navigation. Curr Biol 26:842-847. CrossRef Medline

Howard LR, Javadi AH, Yu Y, Mill RD, Morrison LC, Knight R, Loftus MM, 
Staskute L, Spiers HJ (2014) The hippocampus and entorhinal cortex encode the path and euclidean distances to goals during navigation. Curr Biol 24:1331-1340. CrossRef Medline

Jacobs J (2014) Hippocampal theta oscillations are slower in humans than in rodents: implications for models of spatial navigation and memory. Philos Trans R Soc Lond B Biol Sci 369:20130304. CrossRef Medline

Jacobs J, Kahana MJ (2010) Direct brain recordings fuel advances in cognitive electrophysiology. Trends Cogn Sci 14:162-171. CrossRef Medline

Jacobs J, Lee SA (2016) Spatial cognition: grid cells support imagined navigation. Curr Biol 26:R277-R279. CrossRef Medline

Jacobs J, Weidemann CT, Miller JF, Solway A, Burke JF, Wei XX, Suthana N, Sperling MR, Sharan AD, Fried I, Kahana MJ (2013) Direct recordings of grid-like neuronal activity in human spatial navigation. Nat Neurosci 16:1188-1190. CrossRef Medline

Jacobs J, Miller J, Lee SA, Coffey T, Watrous AJ, Sperling MR, Sharan A, Worrell G, Berry B, Lega B, Jobst BC, Davis K, Gross RE, Sheth SA, Ezzyat Y, Das SR, Stein J, Gorniak R, Kahana MJ, Rizzuto DS (2016) Direct electrical stimulation of the human entorhinal region and hippocampus impairs memory. Neuron 92:983-990. CrossRef Medline

Julian JB, Keinath AT, Muzzio IA, Epstein RA (2015) Place recognition and heading retrieval are mediated by dissociable cognitive systems in mice. Proc Natl Acad Sci U S A 112:6503-6508. CrossRef Medline

Julian JB, Ryan J, Hamilton RH, Epstein RA (2016) The occipital place area is causally involved in representing environmental boundaries during navigation. Curr Biol 26:1104-1109. CrossRef Medline

Killian NJ, Jutras MJ, Buffalo EA (2012) A map of visual space in the primate entorhinal cortex. Nature 491:761-764. CrossRef Medline

Krupic J, Bauza M, Burton S, Barry C, O'Keefe J (2015) Grid cell symmetry is shaped by environmental geometry. Nature 518:232-235. CrossRef Medline

Lakusta L, Dessalegn B, Landau B (2010) Impaired geometric reorientation caused by genetic defect. Proc Natl Acad Sci U S A 107:2813-2817. CrossRef Medline

Lee SA (2017) The boundary-based view of spatial cognition: a synthesis. Curr Opin Behav Sci 16:58-65. CrossRef

Lee SA, Spelke ES (2008) Children's use of geometry for reorientation. Dev Sci 11:743-749. CrossRef Medline

Lee SA, Spelke ES (2010) Two systems of spatial representation underlying navigation. Exp Brain Res 206:179-188. CrossRef Medline

Lee SA, Shusterman A, Spelke ES (2006) Reorientation and landmarkguided search by young children: evidence for two systems. Psychol Sci 17:577-582. CrossRef Medline

Lee SA, Spelke ES (2011) Young children reorient by computing layout geometry, not by matching images of the environment. Psychon Bull Rev 18:192-198. CrossRef Medline

Lever C, Wills T, Cacucci F, Burgess N, O'Keefe J (2002) Long-term plasticity in hippocampal place-cell representation of environmental geometry. Nature 416:90-94. CrossRef Medline

Lever C, Burton S, Jeewajee A, O'Keefe J, Burgess N (2009) Boundary vector cells in the subiculum of the hippocampal formation. J Neurosci 29:97719777. CrossRef Medline

Maurer AP, Vanrhoads SR, Sutherland GR, Lipa P, McNaughton BL (2005) Self-motion and the origin of differential spatial scaling along the septotemporal axis of the hippocampus. Hippocampus 15:841-852. CrossRef Medline

McFarland WL, Teitelbaum H, Hedges EK (1975) Relationship between hippocampal theta activity and running speed in the rat. J Comp Physiol Psychol 88:324-328. CrossRef Medline

McNaughton BL, Barnes CA, O'Keefe J (1983) The contributions of position, direction, and velocity to single unit activity in the hippocampus of freely-moving rats. Exp Brain Res 52:41-49. Medline

Miller JF, Neufang M, Solway A, Brandt A, Trippel M, Mader I, Hefft S, Merkow M, Polyn SM, Jacobs J, Kahana MJ, Schulze-Bonhage A (2013) Neural activity in human hippocampal formation reveals the spatial context of retrieved memories. Science 342:1111-1114. CrossRef Medline
Muessig L, Hauser J, Wills TJ, Cacucci F (2015) A developmental switch in place cell accuracy coincides with grid cell maturation. Neuron 86:11671173. CrossRef Medline

Nyhus E, Curran T (2010) Functional role of gamma and theta oscillations in episodic memory. Neurosci Biobehav Rev 34:1023-1035. CrossRef Medline

O'Keefe J, Burgess N (1996) Geometric determinants of the place fields of hippocampal neurons. Nature 381:425-428. CrossRef Medline

O'Keefe, J., and Nadel, L (1978) The hippocampus as a cognitive map. New York, NY: OUP.

Olson JM, Tongprasearth K, Nitz DA (2017) Subiculum neurons map the current axis of travel. Nat Neurosci 20:170-172. CrossRef Medline

Omer DB, Maimon SR, Las L, Ulanovsky N (2018) Social place-cells in the bat hippocampus. Science 359:218-224. CrossRef Medline

Park S, Brady TF, Greene MR, Oliva A (2011) Disentangling scene content from spatial boundary: complementary roles for the parahippocampal place area and lateral occipital complex in representing real-world scenes. J Neurosci 31:1333-1340. CrossRef Medline

Pfeiffer BE, Foster DJ (2013) Hippocampal place-cell sequences depict future paths to remembered goals. Nature 497:74-79. CrossRef Medline

Rivas J, Gaztelu JM, García-Austt E (1996) Changes in hippocampal cell discharge patterns and theta rhythm spectral properties as a function of walking velocity in the guinea pig. Exp Brain Res 108:113-118. Medline

Rolls ET (1999) Spatial view cells and the representation of place in the primate hippocampus. Hippocampus 9:467-480. CrossRef Medline

Solstad T, Boccara CN, Kropff E, Moser MB, Moser EI (2008) Representation of geometric borders in the entorhinal cortex. Science 322:18651868. CrossRef Medline

Spelke E, Lee SA, Izard V (2010) Beyond core knowledge: natural geometry. Cogn Sci 34:863-884. CrossRef Medline

Stensola T, Stensola H, Moser MB, Moser EI (2015) Shearing-induced asymmetry in entorhinal grid cells. Nature 518:207-212. CrossRef Medline

Stewart S, Jeewajee A, Wills TJ, Burgess N, Lever C (2014) Boundary coding in the rat subiculum. Philos Trans R Soc Lond B Biol Sci 369:20120514. CrossRef Medline

Tang Q, Burgalossi A, Ebbesen CL, Ray S, Naumann R, Schmidt H, Spicher D, Brecht M (2014) Pyramidal and stellate cell specificity of grid and border representations in layer 2 of medial entorhinal cortex. Neuron 84: 1191-1197. CrossRef Medline

Terrazas A, Krause M, Lipa P, Gothard KM, Barnes CA, McNaughton BL (2005) Self-motion and the hippocampal spatial metric. J Neurosci 25: 8085-8096. CrossRef Medline

Tolman EC (1948) Cognitive maps in rats and men. Psychol Rev 55:189208. CrossRef Medline

Tommasi L, Chiandetti C, Pecchia T, Sovrano VA, Vallortigara G (2012) From natural geometry to spatial cognition. Neurosci Biobehav Rev 36: 799-824. CrossRef Medline

Vass LK, Copara MS, Seyal M, Shahlaie K, Farias ST, Shen PY, Ekstrom AD (2016) Oscillations go the distance: low-frequency human hippocampal oscillations code spatial distance in the absence of sensory cues during teleportation. Neuron 89:1180-1186. CrossRef Medline

Wang H, Suh JW, Das SR, Pluta JB, Craige C, Yushkevich PA (2013) Multiatlas segmentation with joint label fusion. IEEE Trans Pattern Anal Mach Intell 35:611-623. CrossRef Medline

Watrous AJ, Fried I, Ekstrom AD (2011) Behavioral correlates of human hippocampal delta and theta oscillations during navigation. J Neurophysiol 105:1747-1755. CrossRef Medline

Watrous AJ, Tandon N, Conner CR, Pieters T, Ekstrom AD (2013) Frequencyspecific network connectivity increases underlie accurate spatiotemporal memory retrieval. Nat Neurosci 16:349-356. CrossRef Medline

Yushkevich PA, Pluta JB, Wang H, Xie L, Ding SL, Gertje EC, Mancuso L, Kliot D, Das SR, Wolk DA (2015) Automated volumetry and regional thickness analysis of hippocampal subfields and medial temporal cortical structures in mild cognitive impairment. Hum Brain Mapp 36:258-287. CrossRef Medline 